charity, the International Glaucoma Association, has included in its aims both the improvement of the general awareness of glaucoma, especially among those concerned with primary eye care $^{20}$ and the encouragement of even closer collaboration among general practitioners, ophthalmologists, ophthalmic opticians, nurses and health visitors, medical auxiliaries, patients, and the public.

R P CRICK

Honorary Consultant Ophthalmic Surgeon,

Glaucoma Centre,

King's College Hospital,

London SE5 9RS

1 Sorsby A. The incidence and causes of blindness in England and Wales. 1958-62. London: HMSO, 1966. (Reports on Public Health and Medical Subjects, No 114.)

2 Sorsby A. The incidence and causes of blindness in England and Wales. 1963-68. With an appendix on services available for incipient blindness. London: HMSO, 1972. (Reports on Public Health and Medical Subjects, No 128.)

${ }^{3}$ Wilson R, Walker AM, Dueker DK, Crick RP. Risk factors for rate of progression of glaucomatous visual field loss: a computer-based analysis. Arch Ophthalmol 1982;100;737-41.

4 Galin MA. Elevated intraocular pressure-the importance of early treatment. Research and Clinical Forums (in press).

${ }^{5}$ Crick RP. Computerised monitoring of glaucoma. In: Bellows JG, ed. Glaucoma. Contemporary international concepts. New York: Masson, 1980:185-96.

- Aulhorn E, Karmeyer H. Frequency distribution in early glaucomatous visual field defects. Doc Ophthalmol 1976;14:75-83.

${ }^{7}$ Hollows FC, Graham PA. The Ferndale glaucoma survey. In: Hunt LB, ed. Glaucoma. Edinburgh: Livingstone, 1966:24-44.

${ }^{8}$ Bankes JLK, Perkins ES, T solakis S, Wright JE. Bedford glaucoma survey. Br Med f 1968;i:791-6.

- Crick RP. Glaucoma - the present situation. Practitioner 1980;224:621-30.

10 Daubs JG, Crick RP. Blindness prevention through control of ocular hypertension: an epidemiological assessment. Int Ophthalmol Clin 1980; 3:43-9.

11 Miller SJH, Paterson GD. Studies on glaucoma relatives. Br $\mathcal{F}$ Ophthalmol $1962 ; 46: 513-22$.

12 Coakes RL. The role of a family glaucoma clinic. Research and Clinical Forums $1980 ; 2: 15-9$.

${ }^{13}$ Hitchings RA. Glaucoma family screening. Research and Clinical Forums $1980 ; 2: 21-4$

${ }^{14}$ Lieb WA, Stark N, Jelinek MB, Malzi R. Diabetes mellitus und glaukom. Acta Ophthalmol (Copenh) 1967;suppl 94.

15 Armstrong JR, Daily RK, Dobson HI, Girard LJ. The incidence of glaucoma in diabetes mellitus. A comparison with the incidence of glaucoma in the general population. Am F Ophthalmol 1960;50:55-63.

${ }^{18}$ Daubs JG, Crick RP. Effect of refractive error on the risk of ocular hypertension and open angle glaucoma. Trans Ophthalmol Soc UK 1981;101: 121-6.

${ }^{17}$ Maclure GM. Aspects of the investigation and treatment of glaucoma. In: Proceedings of the African eye symposium, Nairobi. 1982:163-200.

18 Crick RP, Creaby E, Freeman S. Who detects primary open angle glaucoma in the United Kingdom ? Fournal of the Association of Dispensing Opticians (in press).

${ }^{19}$ Greve EL, Verduin WM. Detection of early glaucomatous damage. Part II. Cupping and visual field. Doc Ophthalmol 1976;14:115-20.

${ }^{20}$ Leydhecker W, Crick RP. All about glaucuma. London: Faber and Faber, 1981.

\section{The nature of piles}

Few who reach middle age can claim never to have had any symptoms related to the anus. Thomson ${ }^{1}$ has shown elegantly, if not originally, that what many regard as piles are normal vascular cushions. We all have them, and they are as natural as the vascular cushions at the upper end of the alimentary tract that we call lips. We are prepared to accept a wide variety of lips: thin lips, pouting lips, petulant lips, wet lips, and even hot lips. Similarly, variations in the vascular cushions at the anus should possibly be regarded as signs of character rather than disease. Furthermore, the degree of congestion of our cushions depends on factors as varied as hormonal, biochemical, emotional, and, for all I know, barometric. Who can say then what is the incidence of piles in the population? Perhaps the most accurate we can be is to say that they are ubiquitous.

What we, as doctors, are concerned with is not an anatomical or pathological entity but a collection of symptoms. The very words we use imply this. "Piles" comes from the Latin for a pill or a ball and implies the complaint of a lump, either a prolapsed or thrombosed cushion. "Haemorrhoids" comes from the Greek for the flowing of blood-a symptom if ever there was one. To the layman and the comedian, piles implies pain, though pedantic proctological purists may deny this. To those symptoms mentioned we must add, for completeness, itching and discharge. One or more of the five constitute what our patients mean when they "suffer from piles."

What converts these normal functional God-given cushions to symptomatic monsters? The two principal factors are the laxity of the fixation of the vascular mucosa to the wall of the rectum and upper anal canal and the muscular tone or tightness of the anal sphincter. The fixation of mucosal cushions is normally very lax, like the skin at the back of a kitten's neck. The cushions may even have muscular fibres within them that pull the cushion back to the safety of the upper anal canal after defecation. ${ }^{1}$ Once the anal cushions are submitted to congestion they hypertrophy with engorgement-just as do the upper alimentary lips of some African ladies who value labial hypertrophy and use metal or leather constriction to achieve it. The anal canal may be tight because of muscle tone or, some would have us believe, fibrosis. ${ }^{2}$ What causes variations in tone is not clear, but measurement of resting pressures in the anal canal indicates that they are normally higher below the age of 60 . I suspect that emotional tension plays a part and I have a syndrome that I designate with the eponym YETAS, the "Young executive tight-anus syndrome." Certainly this seems to be one group of people prone to piles; others are golfers and professional cricketers.

In addition to spasm there may be true fibrosis in the anal sphincters, though this has never been shown histologically. An easily confirmed observation from life's vast store of observables is that young children, left to their own devices, will pass stools of such a width as to frighten their mother but not daunt themselves. The close ratio of stool-to-arm diameter in childhood must surely be normal. In the Western developed world, the much smaller ratio in adults probably represents the sequel of an unbalanced diet. Men who supplement, or substitute for, their food with cathartic beers often have anal symptoms, though I must admit that the lesions are more often perianal dermatitis or fissure than piles. I use for this another eponym, "bitterman's bottom." Such patients' anal symptoms respond dramatically to the restoration of anal resilience and elasticity that follows a manual dilatation.

The secondary pathological changes that accompany protrusion and congestion provoke the complications and principal symptoms of piles. Congestion may cause discomfort from increasing tissue tension; hypertrophy facilitates further protrusion and impedes withdrawal into the anal canal. The congested cushions are easily injured and bleed as readily and as vividly as does a cut lip. Severe unrelieved congestion predisposes to thrombosis giving rise to that proctological "full-house," strangulated piles.

Cushions that are so large that they do not return to the anal canal after defecation will leave exposed mucous membrane with consequent discharge and skin maceration; bacterial or fungal invasion may then cause pruritus.

An understanding of the nature of piles and the causation of symptoms enables us to devise rational treatment. If we accept that mucosal laxity and sphincter congestion are the two 
principal causes of the condition, it seems illogical to use local greasy applications or haemorrhoidectomy as the mainstay of treatment. Yet throughout the world, until recent years, classical medicine has espoused these methods. Many of the enlightened now regard both treatments as refuges of the proctologically destitute. They still have a place, but only within the whole armament of stool-bulking agents, anal dilatation, sphincterotomy, and mucosal fixation by fire, oil, or frost.

J AlEXANDER-WILliamS

Consultant Surgeon,

General Hospital,

Birmingham B4 6NH

1 Thomson WHF. The nature of haemorrhoids. Br $\mathcal{F}$ Surg 1975;62:542-52.

2 Lord PH. Conservative management of haemorrhoids : 2-dilatation treatment. Clin Gastroenterol 1975;4:401-8.

\section{Does control of risk factors prevent coronary heart disease?}

The seven-year American Multiple Risk Factor Intervention Trial has ended with inconclusive results-and leaving many questions unanswered. ${ }^{1}$ Whether intervention to control cigarette smoking, hypertension, and hypercholesterolaemia alters mortality from coronary heart disease in men at high risk remains uncertain. And an appalling consequence of these results is that the central question is likely to remain unresolved indefinitely, for this vast trial, costing $\$ 115$ million and based on 28 institutions with 250 investigators, is unlikely ever to be repeated.

The trial population was 12866 men, selected from 361662 men who volunteered for health screening through their employment. The 12866 represented the upper $15 \%$ of a risk score distribution (two-thirds were in the upper 10\%) based on smoking, blood pressure, and plasma cholesterol concentration. None had clinical or electrocardiographic evidence of coronary heart disease.

Half the selected group was randomly allocated to an intensive intervention programme conducted by behavioural scientists, nutritionists, nurses, physicians, and health counsellors; they were seen every four months or more frequently to ensure adequate control of the risk factors. The other half received a medical examination once yearly and no specific advice about control of risk factors, other than that given by their doctors. Randomisation of characteristics associated with coronary heart disease was excellent and established that the two groups were comparable on admission to the trial. Less than $10 \%$ of each group was lost to follow-up over the first six years.

In the intervention group simultaneous intervention programmes were mounted to stop cigarette smoking, to control raised blood pressure (mostly with thiazides), and to alter the diet to reduce hypercholesterolaemia. Initially, the aim of the dietary changes was to reduce the intake of saturated fat to less than $10 \%$ of energy and the daily intake of cholesterol to less than $300 \mathrm{mg}$; later these limits were narrowed to less than $8 \%$ of energy and $250 \mathrm{mg}$ of cholesterol.

After six years half of the men in the intervention group had stopped smoking ( $43 \%$ at one year), the mean diastolic blood pressure had fallen from $91 \mathrm{~mm} \mathrm{Hg}$ to $81 \mathrm{~mm} \mathrm{Hg}$ (and by $12 \%$ in those initially with $95 \mathrm{~mm} \mathrm{Hg}$ or more), and the average plasma cholesterol concentration was reduced from $6.2 \mathrm{mmol} / 1$ $(240 \mathrm{mg} / 100 \mathrm{ml})$ by $0.3 \mathrm{mmol} / 1(12 \mathrm{mg} / 100 \mathrm{ml})-5 \%$. Substantial decreases also occurred in all risk factors in the nonintervention group, but statistically significant differences were achieved between the intervention and non-intervention groups in each of the three major risk factors at each annual visit. The difference in cigarette smoking between the groups exceeded the goal of the trial. The difference in diastolic blood pressure was, however, only three-quarters of the design goal, and for cholesterol only half of the goal-a difference of no more than $0.1 \mathrm{mmol} / 1(4.6 \mathrm{mg} / 100 \mathrm{ml})$.

An analysis based on averaging calculated coronary heart disease risk for each participant over the six years of follow-up indicated a potential net reduction of mortality of $22 \%$ (compared with a projected $27 \%$ ) between the groups as a result of the difference in reduction of risk factors, but no significant reduction in mortality was actually achieved.

What, then, went wrong? The investigators had not expected any decreases in risk factors in the non-intervention group; it was a major miscalculation that the design of the Multiple Risk Factor Intervention Trial did not allow for any change in blood pressure or cholesterol concentrations in this group. The investigators seriously underestimated the effects on high-risk men of knowledge of that risk, of the influence of those in the intervention group on those in the non-intervention group in the same industry or office, of annual reviews in the framework of the trial, and of providing doctors with annual reports and data on their patients' progress in the trial. The non-intervention group also had a lower-than-expected mortality, reducing the chance of detecting a significant difference between the groups. Indeed, the non-intervention group was not a satisfactory control group and this could have been predicted at the outset.

The trial report has some worrying features. Several subgroups have been analysed outside the randomised controlled design; this gives grounds for concern because of the small residual numbers in such subgroups, because some were defined post hoc, and because other confounding factors cannot be controlled. These analyses provide encouragement in only one respect. Non-hypertensive hypercholesterolaemic smokers had a lower $(-49 \%)$ mortality from coronary heart disease in the intervention group than in the non-intervention group, though this difference was not statistically significant. But hypertensive men with initial electrocardiographic abnormalities did worse with higher mortality from coronary heart disease $(+65 \%)$ and total mortality $(+58 \%)$. How much of the excess occurred in thiazide-treated men is not clear. After exclusion of the $28 \%$ with abnormal baseline electrocardiograms all subgroups of risk had fewer deaths from coronary heart disease in the intervention group than the nonintervention group: but even this focusing on the healthiest subsections did not provide any significant differences.

The tenor of the report clearly shows that the investigators were very disappointed with the results. Indeed, a degree of rationalisation is evident in the commentary. Three explanations are offered: firstly, that overall intervention to reduce multiple risk factors in high-risk men does not affect coronary heart disease mortality over seven years; secondly, that it does but concurrent changes in the control group prevented its demonstration; or, thirdly, that some aspects of intensive intervention had a deleterious effect in certain subgroups obscuring a truly beneficial effect in others. The authors favour the last explanation but it seems unlikely that the small numbers with such an adverse response, less than a tenth of the 